\title{
Populations of Nonpathogenic Fusarium oxysporum Associated with Roots of Four Plant Species Compared to Soilborne Populations
}

\author{
V. Edel, C. Steinberg, N. Gautheron, and C. Alabouvette
}

Laboratoire de Recherches sur la Flore Pathogène du Sol, Institut National de la Recherche Agronomique (INRA)-CMSE, 17 rue Sully, BV 1540, 21034 Dijon Cedex, France.

Accepted for publication 7 April 1997.

\begin{abstract}
Edel, V., Steinberg, C., Gautheron, N., and Alabouvette, C. 1997. Populations of nonpathogenic Fusarium oxysporum associated with roots of four plant species compared to soilborne populations. Phytopathology 87: 693-697.

The effect of the plant on the diversity of soilborne populations of Fusarium oxysporum was assessed after successive cultures of flax, melon, tomato, and wheat in separate samples of the same soil. Forty soilborne isolates of $F$. oxysporum and forty root-colonizing isolates of each plant species were sampled during the first (T0) and fourth (T1) cultures. The population structures were assessed by a genotypic method based on restriction fragment analysis of polymerase chain reaction-amplified ri-

among the four hundred isolates analyzed. The distributions of soil isolates among IGS types were similar at both sampling times. The structure of $F$. oxysporum populations associated with the roots of flax or melon did not differ from the structure of soilborne populations. In contrast, the structure of $F$. oxysporum populations associated with roots of wheat or tomato differed from the structure of soilborne populations. High frequencies were found for IGS type 4 among wheat isolates at both T0 and T1 and for IGS type 11 among tomato isolates at T1. Moreover, a high level of genetic divergence was obtained between IGS types 4 and 11. Our results suggest that tomato and wheat have a selective effect on soilborne populations of $F$. oxysporum and that this effect seems to be plant specific.
\end{abstract} bosomal intergenic spacer (IGS) DNA. Sixteen IGS types were defined
Fusarium oxysporum Schlechtend. emend. Snyder \& Hans. is an important component of soil microflora throughout the world. Some strains, known as formae speciales, are pathogenic and are responsible for wilt on various plant species (23). However, soils also harbor large populations of nonpathogenic $F$. oxysporum. Both pathogenic and nonpathogenic strains are able to persist through saprophytic growth on organic matter in soil (7).

The role of nonpathogenic $F$. oxysporum in the natural suppressiveness of some soils to Fusarium wilts has been established $(1,18,27)$ and has led to the screening of effective strains as biocontrol agents $(4,25,26)$. The microbial antagonism between pathogenic and nonpathogenic strains is based principally on competition in soil for nutrients (9) and on roots for colonization sites (12). These modes of action have been studied for model strains, but we do not know the degree to which these model strains represent natural populations of nonpathogenic F. oxysporum. However, soilborne populations of $F$. oxysporum are important, ubiquitous, and, in addition, show a high degree of diversity $(5,10,11,14)$.

In soilless cropping systems, selected $F$. oxysporum strains provide effective biological control of Fusarium wilts on many plants of economic importance when high densities of inoculant are introduced into artificial substratum (3). In contrast, such efficacy of biological control is not achieved in soil. This lack of efficacy in disease control may be related to competitive interactions with indigenous microflora and may be ascribed to inefficient rhizosphere and root colonization by the introduced strain.

In addition to resident microbial populations, the plant itself may play an important role in the competition for root colonization. A wide range of interactions occurs between the soil microflora and

Corresponding author: V. Edel; E-mail address: edel@dijon.inra.fr

Publication no. P-1997-0506-01R

(C) 1997 The American Phytopathological Society roots, which can stimulate microbial densities and activities (20). This stimulation may be selective toward particular populations of microorganisms and may vary from one plant species to another $(19,22)$. However, whether different plant species are able to influence the diversity of soilborne populations of $F$. oxysporum in their own rhizosphere and select specific subpopulations associated with their roots is unknown. This question is of great interest, because a superior rhizosphere-colonizing isolate of nonpathogenic $F$. oxysporum found in natural soil could have a competitive advantage over the soil microflora and might offer protection from soilborne pathogens.

The aim of the current study was to compare the structure of $F$. oxysporum populations of an uncultivated soil with the structure of populations associated with the roots of four plant species cultivated in this soil. The diversity of the populations of soilborne and root-colonizing $F$. oxysporum was assessed by a genotypic method previously described for the characterization of large populations of $F$. oxysporum (10).

\section{MATERIALS AND METHODS}

Soil and plants. A silt loam soil from a fallow field in eastern France (Dijon) was used. The main characteristics of the soil are $35.1 \%$ clay, $47 \%$ loam, $15.1 \%$ sand, $1.22 \%$ organic $\mathrm{C}, 0 \% \mathrm{CaCO}_{3}$, and $\mathrm{pH}$ 6.9. The soil was collected in five 150 -liter containers and placed in a greenhouse under daylight and temperatures of $18^{\circ} \mathrm{C}$ during the night and $22^{\circ} \mathrm{C}$ during the day. Soil in one container was kept uncultivated, and each of the four other containers was seeded with either flax (Linum usitatissimum L. 'Opaline'), melon (Cucumis melo L. 'Tendral'), tomato (Lycopersicon esculentum Mill. 'H63.5'), or wheat (Triticum vulgare Vill. 'Ventura'). Soils were planted to four successive cycles of the same crop, with each cycle consisting of a 2-month growth period followed by a 1-month cropfree period. At the end of each growth period, plants were dug up, and soils were turned over. 
Fungal isolates. Fungal isolation was performed from the uncultivated soil and the roots of each plant species during the first (T0) and fourth (T1) crops. For isolation from soil, three independent replicates were prepared. Each replicate consisted of a pooled homogenized mixture of five samples of soil originating from the five uncultivated containers at the beginning of the experiment (soil at T0) and from the uncultivated container at T1. The soil was air-dried and passed through a $200-\mu \mathrm{m}$ sieve. Subsamples of $\sim 10 \mathrm{mg}$ were spread over Komada's selective medium (17). Four plates were prepared for each replicate and incubated under fluorescent light at room temperature for 7 days. Fusarium colonies were observed microscopically, and those identified as $F$. oxysporum were transferred to potato dextrose agar (PDA). Single-spore isolations were made from each colony, and isolates were reidentified morphologically according to Nelson et al. (24).

For fungal isolation from roots, 10 plants per container were collected. Each plant was washed by hand-shaking in sterile distilled water to remove all adhering soil. Ten root fragments, $0.3 \mathrm{~cm}$ per plant, were excised, blotted onto sterile filter paper to remove water, and placed on Komada's medium. After 5 days of incubation at room temperature, colonies of $F$. oxysporum were transferred to PDA, and single-spore isolations were conducted.

The 10 compartments analyzed correspond to the uncultivated soil and the root system of each of the four plant species at each of the two sampling times (T0 and T1). A total of 400 isolates of $F$. oxysporum, including 40 isolates per compartment, was collected. The collection was stored by cryopreservation at $-80^{\circ} \mathrm{C}$.

Pathogenicity tests. A subsample of 60 isolates of $F$. oxysporum randomly taken from among the 400 isolates was checked for pathogenicity on flax, melon, and tomato. Isolates were grown in malt broth $\left(10 \mathrm{~g} \mathrm{liter}^{-1}\right)$ for 5 days on a rotary shaker at $25^{\circ} \mathrm{C}$. The culture was filtered through $40-\mu \mathrm{m}$ mesh to remove mycelial

TABLE 1. Intergenic spacer (IGS) types and restriction patterns of Fusarium oxysporum isolates revealed by restriction fragment length polymorphism analysis of polymerase chain reaction-amplified IGS sequences

\begin{tabular}{lccccccc}
\hline \multirow{2}{*}{$\begin{array}{l}\text { IGS } \\
\text { type }^{\text {a }}\end{array}$} & \multicolumn{6}{c}{ Restriction patterns of amplified IGS fragments digested with enzymes } \\
\cline { 2 - 8 } & AluI & Hae III & HinfI & MspI & RsaI & ScrFI & XhoI \\
\hline 1 & 1 & 1 & 1 & 1 & 1 & 1 & 1 \\
2 & 1 & 1 & 2 & 1 & 1 & 1 & 1 \\
3 & 1 & 1 & 2 & 1 & 1 & 1 & 2 \\
4 & 2 & 1 & 2 & 1 & 1 & 1 & 2 \\
5 & 1 & 1 & 2 & 1 & 1 & 2 & 2 \\
6 & 1 & 2 & 2 & 1 & 1 & 1 & 1 \\
7 & 1 & 3 & 2 & 1 & 2 & 1 & 1 \\
8 & 3 & 4 & 1 & 1 & 1 & 2 & 1 \\
9 & 4 & 4 & 1 & 2 & 1 & 2 & 1 \\
10 & 4 & 4 & 1 & 3 & 3 & 3 & 1 \\
11 & 5 & 5 & 1 & 3 & 4 & 4 & 1 \\
12 & 1 & 6 & 2 & 4 & 1 & 1 & 2 \\
13 & 6 & 4 & 1 & 1 & 1 & 2 & 1 \\
14 & 1 & 3 & 3 & 1 & 2 & 1 & 1 \\
15 & 1 & 2 & 4 & 1 & 1 & 1 & 1 \\
16 & 2 & 1 & 2 & 1 & 5 & 1 & 2 \\
\hline
\end{tabular}

a IGS types represent the combination of patterns obtained with the seven restriction enzymes.

b Numbers designate the various patterns obtained for each restriction enzyme. fragments, and the suspension was adjusted to $9 \times 10^{5}$ conidia per $\mathrm{ml}$. For each isolate, three independent conidial suspensions originating from three independent precultures were prepared. The plants were grown in environment-controlled chambers. The temperature of the chambers was regulated at $20^{\circ} \mathrm{C}$ during the night $(9 \mathrm{~h})$ and $26^{\circ} \mathrm{C}$ during the day $(15 \mathrm{~h}, 13,000 \mathrm{lux})$ for flax, at $20^{\circ} \mathrm{C}$ during the night $(12 \mathrm{~h})$ and $25^{\circ} \mathrm{C}$ during the day $(12 \mathrm{~h}, 12,000 \mathrm{lux})$ for melon, and at $22^{\circ} \mathrm{C}$ during the night $(10 \mathrm{~h})$ and $25^{\circ} \mathrm{C}$ during the day $(14 \mathrm{~h}$, 10,000 lux) for tomato. The relative humidity in the chambers was maintained at $60 \%$ during the night and $80 \%$ during the day for all plant species. Each plant was grown on a 9-ml rockwool plug wetted twice a day with nutrient solution. Two weeks after sowing, each plant was inoculated with $1 \mathrm{ml}$ of the conidial suspension. Each conidial suspension was used to inoculate 6 replicate plants, resulting in 18 inoculated plants per isolate. Controls consisted of plants inoculated with reference strains of $F$. oxysporum pathogenic on flax, melon, and tomato (strains Foln3, Fom15, and Fol32, respectively, from the FPFS Culture Collection, INRA, Dijon, France).

Genotypic characterization. The procedure used to characterize the 400 isolates of $F$. oxysporum was previously described (10). This method is based on restriction fragment length polymorphism (RFLP) analysis of ribosomal DNA. A fragment of the intergenic spacer (IGS) was amplified by polymerase chain reaction (PCR) with oligonucleotide primers PNFO (5'-CCCGCCTGGCTGCGTCCGACTC-3') and PN22 (5'-CAAGCATATGACTACTGGC-3') and digested with seven restriction enzymes: AluI, HaeIII, HinfI, MspI, RsaI, ScrFI, and XhoI. Each isolate was assigned to an IGS type defined by the combination of the restriction patterns obtained with the seven enzymes. The genetic relationships between IGS types were inferred from the differences in restriction sites in the IGS sequences, as previously described (10), by Dollo parsimony (28).

The distributions of the 40 isolates from the different compartments among the different IGS types were compared with Fisher's exact test by the computer program STATXACT (Cytel Software Corporation, version 2.11, Cambridge, MA). This nonparametric test was chosen because of the small number of isolates in some IGS types. It is based on permutations to test for row and column independence in a contingency table. Our data corresponded to the number of isolates per IGS type in each compartment, so the row and column classifications are the compartments and the IGS types, respectively. The program computes the exact $P$ values to test the hypothesis of random distributions. If the $P$ value is smaller than 0.05 , the hypothesis is rejected, indicating that the distributions of isolates among IGS types are not independent of their compartment of origin.

\section{RESULTS}

Population structure. None of the 60 isolates of F. oxysporum tested was pathogenic on the three plant species tested, and no Fusarium wilt symptoms were observed on any plant cultivated in the containers. Thus, all isolates included in this study were con-

TABLE 2. Number of isolates of Fusarium oxysporum belonging to different intergenic spacer (IGS) types for each compartment analyzed

\begin{tabular}{|c|c|c|c|c|c|c|c|c|c|c|c|c|c|c|c|c|c|}
\hline \multirow{2}{*}{$\begin{array}{l}\text { Time of } \\
\text { isolation }\end{array}$} & \multirow{2}{*}{$\begin{array}{c}\text { Compartment } \\
\text { of origin }\end{array}$} & \multicolumn{16}{|c|}{ Number of isolates per IGS type } \\
\hline & & 1 & 2 & 3 & 4 & 5 & 6 & 7 & 8 & 9 & 10 & 11 & 12 & 13 & 14 & 15 & 16 \\
\hline \multirow[t]{5}{*}{ T0 } & Soil & 10 & 2 & 8 & 9 & 0 & 0 & 0 & 1 & 2 & 0 & 6 & 0 & 0 & 1 & 1 & 0 \\
\hline & Flax roots & 4 & 0 & 5 & 12 & 4 & 0 & 0 & 4 & 1 & 0 & 7 & 0 & 0 & 0 & 2 & 1 \\
\hline & Melon roots & 5 & 1 & 7 & 13 & 1 & 0 & 1 & 2 & 3 & 0 & 3 & 0 & 0 & 0 & 3 & 1 \\
\hline & Tomato roots & 9 & 0 & 2 & 7 & 1 & 0 & 0 & 1 & 7 & 0 & 7 & 0 & 1 & 1 & 3 & 1 \\
\hline & Wheat roots & 2 & 0 & 3 & 23 & 0 & 0 & 1 & 5 & 1 & 0 & 2 & 1 & 0 & 0 & 2 & 0 \\
\hline \multirow[t]{5}{*}{$\mathrm{T} 1$} & Soil & 8 & 0 & 9 & 5 & 0 & 0 & 1 & 3 & 4 & 3 & 6 & 0 & 0 & 0 & 0 & 1 \\
\hline & Flax roots & 7 & 0 & 6 & 10 & 1 & 1 & 0 & 1 & 7 & 0 & 6 & 0 & 0 & 0 & 0 & 1 \\
\hline & Melon roots & 8 & 2 & 7 & 5 & 3 & 1 & 0 & 1 & 5 & 0 & 6 & 2 & 0 & 0 & 0 & 0 \\
\hline & Tomato roots & 8 & 0 & 3 & 8 & 1 & 0 & 0 & 3 & 1 & 0 & 16 & 0 & 0 & 0 & 0 & 0 \\
\hline & Wheat roots & 5 & 0 & 6 & 15 & 0 & 0 & 0 & 3 & 4 & 0 & 5 & 0 & 1 & 0 & 1 & 0 \\
\hline
\end{tabular}


sidered nonpathogenic. The 400 isolates collected from the uncultivated soil and the root systems of the four plant species were characterized by PCR/RFLP analysis of IGS DNA. Oligonucleotide primers PNFO and PN22 permitted the amplification of a single DNA fragment of $\sim 1,700 \mathrm{bp}$ for each of the 400 isolates. No size variation in the PCR product was observed between isolates. The PCR products were digested with each of the seven restriction enzymes. Each enzyme yielded between 3 and 20 restriction fragments, with the exception of XhoI, which had no site or one site in the amplified fragment. Depending on the enzyme, two to six distinct restriction patterns were obtained. Sixteen different combinations of patterns representing sixteen IGS types were identified among the four hundred isolates (Table 1). The numbers assigned to IGS types 1 to 11 follow those previously described on a subcollection of 60 isolates (10). In the current study, five new IGS types were obtained.

For each of the compartments analyzed, the number of isolates in each IGS type is given in Table 2. The 40 soil isolates were distributed in 9 IGS types at both T0 and T1. The highest frequency found for one IGS type within soil populations was $25 \%$ at T0 (IGS type 1) and $22.5 \%$ at T1 (IGS type 3). The statistical analysis indicated no significant differences between distributions of soil isolates at $\mathrm{T} 0$ and $\mathrm{T} 1$.

The number of distinct IGS types recorded among the 40 isolates associated with the root systems varied from 9 (flax and wheat roots) to 11 (melon and tomato roots) at T0 and from 7 (tomato roots) to 10 (melon roots) at T1. For each plant species and isolation time, distributions of root isolates and soil isolates among IGS types were compared. Distributions of root isolates from flax and melon were not different from the distribution of soil isolates, neither at $\mathrm{T} 0$ nor at $\mathrm{T} 1$. In contrast, the distribution of isolates from wheat roots was significantly different from the distribution of soil isolates at T0 (Figure 1). An important difference was found in the frequencies of IGS type 4, which included $57.5 \%$ of the wheat isolates at T0 but only $22.5 \%$ of the soil isolates. At T1, the differences between the distributions of soil and wheat isolates were not significant. However, IGS type 4 was still the most frequent type among wheat isolates $(37.5 \%)$ at $\mathrm{T} 1$ and was three times more frequent than among soil isolates (12.5\%). Finally, the distributions of tomato and soil isolates were significantly different at $\mathrm{T} 1$ but not at $\mathrm{T} 0$. The main difference recorded between these populations was in the proportion of isolates in IGS type 11. This type included only $15 \%$ of the soil isolates at T1 but was the most abundant type among isolates associated with tomato roots, including $40 \%$ of the isolates.

Genetic relationships between IGS types. The map locations of restriction sites in the IGS region were inferred from restriction patterns, known IGS sequences, and previously published data (10). A total of 74 restriction sites, including 29 polymorphic sites, was examined among the 16 IGS types analyzed with seven restriction enzymes. There was no evidence of intragenomic variation in restriction patterns between the copies of the IGS region within the 400 isolates investigated. Dollo parsimony was used to assess the relationships among IGS types from the data matrix (Table 3). Heuristic and branch-and-bound searches yielded identical results. Five equally parsimonious trees were obtained with forty-four steps or restriction site changes. These trees showed few differences in topology. The tree resulting from the bootstrap analysis is presented in Figure 2. Three distinct groups were revealed. The first one included IGS types 1 to 7,12 , and 14 to 16 .
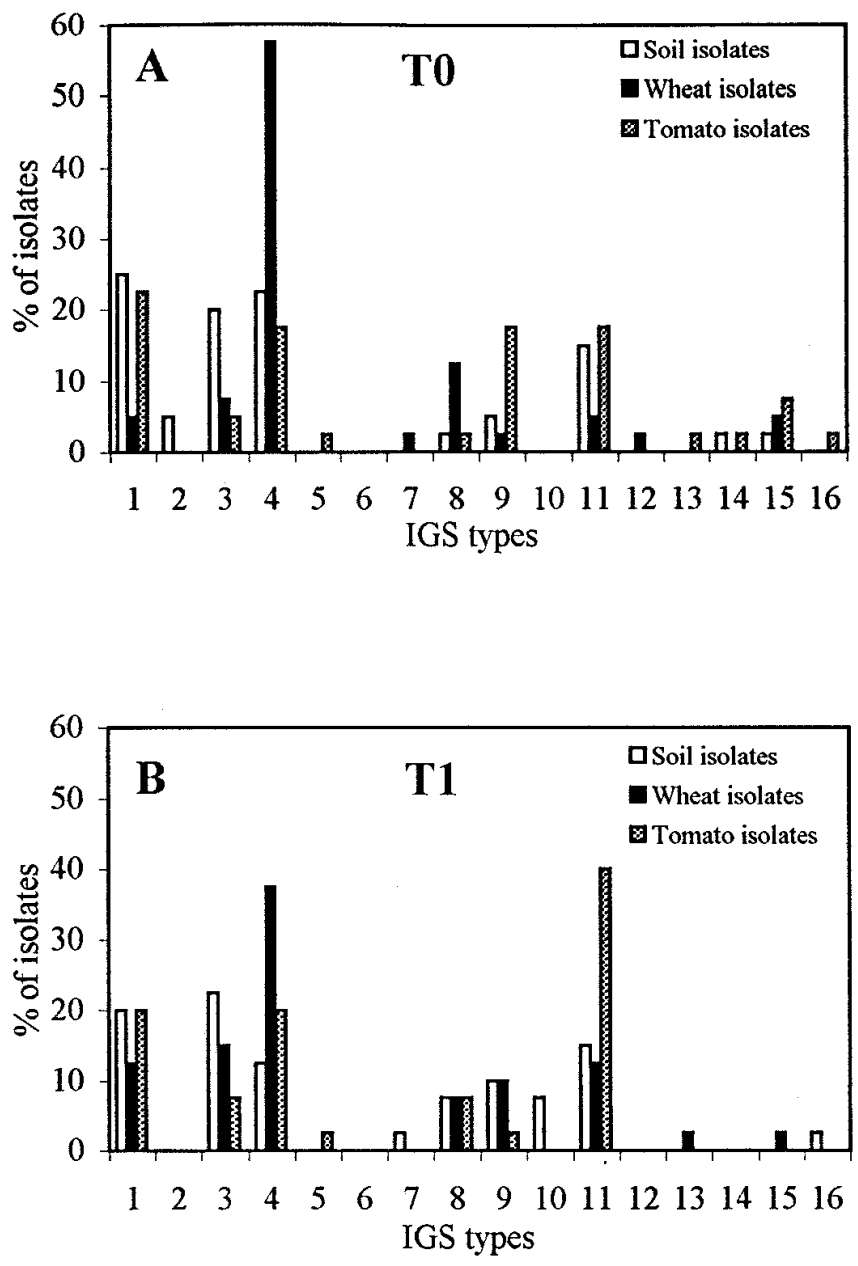

Fig. 1. Distribution among the 16 intergenic spacer (IGS) types (defined in Table 1) of Fusarium oxysporum isolates recovered from soil, wheat roots, and tomato roots at two sampling times: $\mathbf{A}, \mathrm{T} 0$ and $\mathbf{B}, \mathrm{T} 1$.

\begin{tabular}{|c|c|c|c|c|c|c|c|c|c|c|c|c|c|c|c|c|c|c|c|c|c|c|c|c|c|c|c|c|c|}
\hline $\begin{array}{l}\text { IGS } \\
\text { type }\end{array}$ & $\begin{array}{c}\text { RsaI } \\
36\end{array}$ & $\begin{array}{c}S c r F I \\
173\end{array}$ & $\begin{array}{c}M s p \mathrm{I} \\
200\end{array}$ & $\begin{array}{c}\text { HaelII } \\
215\end{array}$ & $\begin{array}{c}\text { RsaI } \\
311\end{array}$ & $\begin{array}{c}\text { XhoI } \\
356\end{array}$ & $\begin{array}{c}A l u \mathrm{I} \\
448\end{array}$ & $\begin{array}{c}\text { ScrFI } \\
502\end{array}$ & $\begin{array}{c}A l u \mathrm{I} \\
593\end{array}$ & $\begin{array}{c}M s p \mathrm{I} \\
620\end{array}$ & $\begin{array}{c}R s a I \\
633\end{array}$ & $\begin{array}{c}R s a \mathrm{I} \\
653\end{array}$ & $\begin{array}{c}\text { HaelII } \\
667\end{array}$ & $\begin{array}{c}S c r F I \\
696\end{array}$ & $\begin{array}{c}\text { Hae III } \\
720\end{array}$ & $\begin{array}{c}\text { HaeIII } \\
742\end{array}$ & $\begin{array}{c}M s p \mathrm{I} \\
756\end{array}$ & $\begin{array}{c}\text { HinfI } \\
764\end{array}$ & $\begin{array}{c}\text { AluI } \\
767\end{array}$ & $\begin{array}{c}M s p \mathrm{I} \\
776\end{array}$ & $\begin{array}{c}\text { AluI } \\
818\end{array}$ & $\begin{array}{c}\text { HaelII } \\
827\end{array}$ & $\begin{array}{c}\text { HaeIII } \\
867\end{array}$ & $\begin{array}{c}\text { HinfI } \\
910\end{array}$ & $\begin{array}{c}\text { AluI } \\
928\end{array}$ & $\begin{array}{c}\text { AluI } \\
968\end{array}$ & $\begin{array}{c}\text { Hae III } \\
982\end{array}$ & $\begin{array}{l}S c r \mathrm{FI} \\
1032\end{array}$ & $\begin{array}{c}\text { HinfI } \\
1174\end{array}$ \\
\hline 1 & 1 & 1 & 1 & 1 & 0 & 1 & 0 & 0 & 0 & 0 & 1 & 0 & 1 & 1 & 0 & 0 & 1 & 1 & 0 & 0 & 0 & 0 & 1 & 0 & 1 & 0 & 1 & 1 & 0 \\
\hline 2 & 1 & 1 & 1 & 1 & 0 & 1 & 0 & 0 & 0 & 0 & 1 & 0 & 1 & 1 & 0 & 0 & 1 & 1 & 0 & 0 & 0 & 0 & 1 & 1 & 1 & 0 & 1 & 1 & 0 \\
\hline 3 & 1 & 1 & 1 & 1 & 0 & 1 & 0 & 0 & 0 & 0 & 1 & 0 & 1 & 1 & 1 & 0 & 1 & 1 & 0 & 0 & 1 & 0 & 1 & 0 & 0 & 0 & 0 & 0 & 0 \\
\hline 4 & 1 & 1 & 1 & 1 & 0 & 0 & 0 & 0 & 1 & 0 & 1 & 0 & 1 & 1 & 0 & 0 & 1 & 1 & 0 & 0 & 0 & 0 & 1 & 1 & 1 & 0 & 1 & 1 & 0 \\
\hline 5 & 1 & 1 & 1 & 1 & 0 & 0 & 0 & 0 & 0 & 0 & 1 & 0 & 1 & 1 & 0 & 0 & 1 & 1 & 0 & 0 & 0 & 0 & 1 & 1 & 1 & 0 & 1 & 0 & 0 \\
\hline 6 & 1 & 1 & 1 & 1 & 0 & 1 & 0 & 0 & 0 & 0 & 1 & 0 & 1 & 1 & 1 & 0 & 1 & 1 & 0 & 0 & 0 & 0 & 0 & 1 & 1 & 0 & 1 & 1 & 0 \\
\hline 7 & 1 & 1 & 1 & 1 & 0 & 1 & 0 & 0 & 0 & 0 & 0 & 0 & 0 & 1 & 1 & 0 & 1 & 1 & 0 & 0 & 0 & 0 & 1 & 1 & 1 & 0 & 0 & 1 & 0 \\
\hline 8 & 1 & 1 & 1 & 1 & 0 & 1 & 0 & 0 & 0 & 0 & 1 & 0 & 1 & 1 & 1 & 0 & 1 & 1 & 0 & 0 & 1 & 0 & 1 & 0 & 0 & 0 & 0 & 0 & 0 \\
\hline 9 & 1 & 1 & 0 & 1 & 0 & 1 & 0 & 0 & 0 & 0 & 1 & 0 & 1 & 1 & 1 & 0 & 1 & 1 & 1 & 0 & 1 & 0 & 1 & 0 & 0 & 0 & 0 & 0 & 0 \\
\hline 10 & 0 & 0 & 0 & 1 & 0 & 1 & 0 & 0 & 0 & 0 & 1 & 0 & 1 & 1 & 1 & 0 & 0 & 1 & 1 & 1 & 1 & 0 & 1 & 0 & 0 & 0 & 0 & 0 & 0 \\
\hline 11 & 1 & 0 & 0 & 0 & 1 & 1 & 1 & 1 & 1 & 0 & 0 & 0 & 1 & 0 & 0 & 0 & 0 & 1 & 0 & 1 & 0 & 1 & 1 & 0 & 1 & 1 & 1 & 0 & 0 \\
\hline 12 & 1 & 1 & 1 & 1 & 0 & 0 & 0 & 0 & 0 & 1 & 1 & 0 & 1 & 1 & 0 & 1 & 1 & 1 & 0 & 0 & 0 & 0 & 1 & 1 & 1 & 0 & 1 & 1 & 0 \\
\hline 13 & 1 & 1 & 1 & 1 & 0 & 1 & 0 & 0 & 0 & 0 & 1 & 0 & 1 & 1 & 1 & 0 & 1 & 1 & 0 & 0 & 1 & 0 & 1 & 0 & 0 & 1 & 0 & 0 & 0 \\
\hline 14 & 1 & 1 & 1 & 1 & 0 & 1 & 0 & 0 & 0 & 0 & 0 & 0 & 0 & 1 & 1 & 0 & 1 & 0 & 0 & 0 & 0 & 0 & 1 & 1 & 1 & 0 & 0 & 1 & 0 \\
\hline 15 & 1 & 1 & 1 & 1 & 0 & 1 & 0 & 0 & 0 & 0 & 1 & 0 & 1 & 1 & 1 & 0 & 1 & 1 & 0 & 0 & 0 & 0 & 0 & 1 & 1 & 0 & 1 & 1 & 1 \\
\hline 16 & 1 & 1 & 1 & 1 & 0 & 0 & 0 & 0 & 1 & 0 & 1 & 1 & 1 & 1 & 0 & 0 & 1 & 1 & 0 & 0 & 0 & 0 & 1 & 1 & 1 & 0 & 1 & 1 & 0 \\
\hline
\end{tabular}

${ }^{a}$ The position of each polymorphic restriction site is numbered from the first nucleotide of the oligonucleotide primer PNFO. The position of the restriction sites missing in the known sequence was approximated. b The IGS types are defined in Table 1. 
Within this group, the relative distances between pairs of IGS types varied from 1.4 to $10.8 \%$ base substitutions in the restriction sites, with an arithmetic mean of 5.4\%. IGS types 8 to 10 and 13 formed the second group, with a mean distance between pairs of IGS types of $5.2 \%$ base substitutions. The third group corresponded to IGS type 11 and was distantly related to all of the other IGS types (18.9 to $24.3 \%$ base substitutions).

\section{DISCUSSION}

The diversity of nonpathogenic populations of $F$. oxysporum isolated from uncultivated soil and the roots of four plant species cultivated in this soil was compared. The PCR-based analysis of the IGS region used in this study was well adapted for large-scale characterization of these populations at the intraspecific level (10). PCR/RFLP methods are less time-consuming and more compatible with broad applications in ecological studies than are methods based on sequencing. Moreover, PCR/RFLP analysis of the IGS was well correlated to two other methods, based on the analysis of DNA fragments dispersed in the whole genome, and was suitable to categorize groups of closely related strains at the population level (10). Appel and Gordon (6) also concluded from sequence data that analysis of variations in the IGS represent a useful approach to resolve interstrain relationships within $F$. oxysporum.

Characterization of IGS types revealed considerable diversity within the populations of $F$. oxysporum in the studied soil. Be-

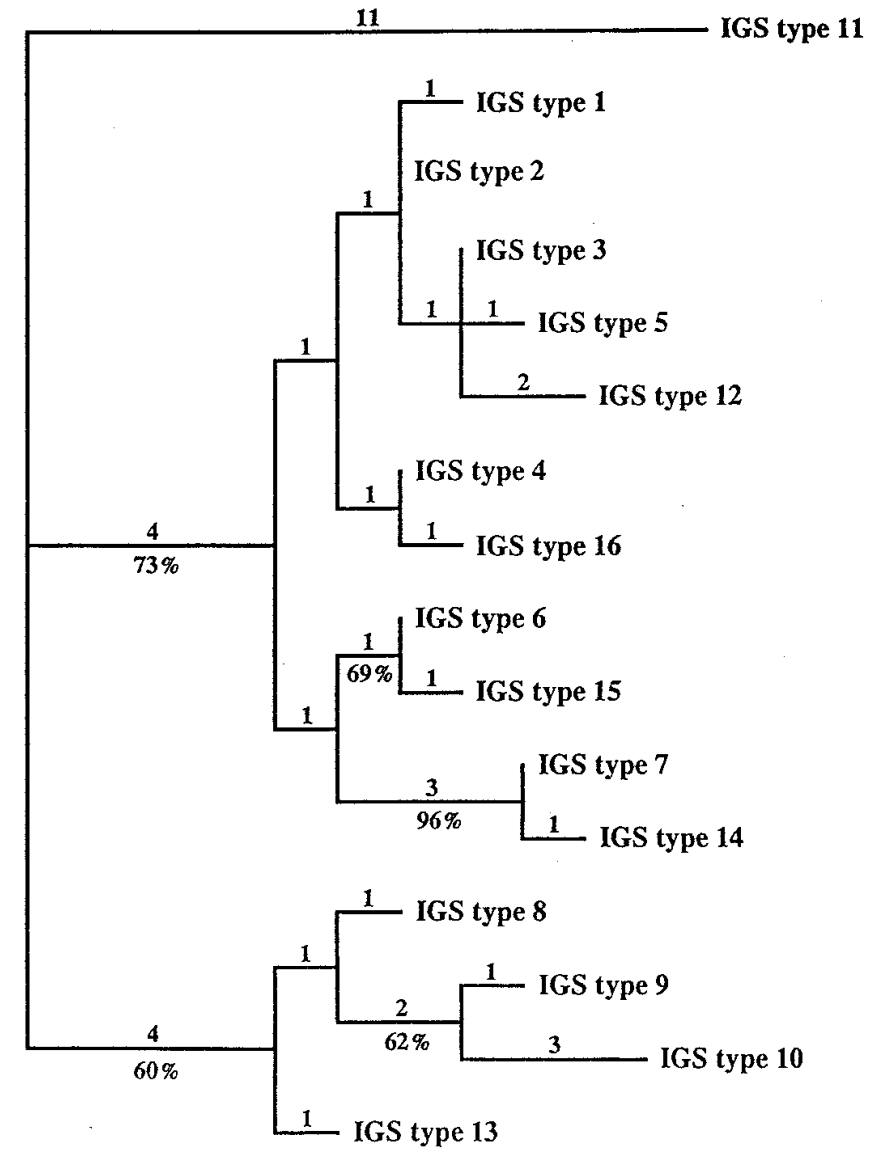

Fig. 2. Tree constructed by the PAUP (28) computer program showing the relationships between the 16 ribosomal intergenic spacer (IGS) types defined in Table 1. The percents below the branches are the frequencies with which a given branch appeared in 500 bootstrap replications. Bootstrap values below $50 \%$ are not displayed. The horizontal branches are drawn proportionally to the number of restriction site changes. The numbers above the branches are the total number of changes assigned to each branch by PAUP. The tree length is 44 steps. cause the distribution of soil isolates among IGS types did not vary with time, one might suggest that soilborne populations were in an equilibrium state that was not disturbed during the experiment. The structure of the populations associated with the roots of wheat and tomato differed from the structure of the populations isolated from the soil. Indeed, frequencies of particular IGS types differed according to the origin of the isolates. IGS type 4 was the most common among wheat isolates and was 2.6 and 3 times more frequent among wheat isolates than among soil isolates at $\mathrm{T} 0$ and $\mathrm{T} 1$, respectively. In contrast, IGS type 11 was the most common type among tomato isolates at $\mathrm{T} 1$ and was 2.7 times more frequent among tomato isolates than among soil isolates. Our results suggest that wheat and tomato plants have a selective effect on populations of $F$. oxysporum through their root systems, each plant species favoring specific populations. This effect was expressed from the first crop of wheat but only from the fourth crop of tomato. The selection of populations belonging to IGS type 4 by wheat already during the first crop could be ascribed to the strong ability of these populations to colonize the wheat root system, whereas the delayed selection of populations belonging to IGS type 11 by tomato could be ascribed to a progressive increase of these populations due to the release of specific exudates. To assess these hypotheses, (i) the root colonization ability of IGS type 4 isolates and other isolates could be compared using wheat and other plant species, and (ii) the evolution of the population structure in the soil cultivated with tomato could be evaluated after several cultures of tomato to determine whether this plant species contributed to the increased frequency of IGS type 11 in the cultivated soil. These hypotheses currently are being evaluated.

In contrast to the results obtained with wheat and tomato, no differences were recorded between the structure of soilborne populations and the structure of populations isolated from flax or melon. These results agree with those of Gordon and Okamoto (15) who stressed the absence of differences between populations of $F$. oxysporum associated with melon roots and populations isolated from soil. Gilbert et al. (13) suggested that roots harboring microbial communities more similar to those present in the surrounding soil would be poorly attractive for pathogens. This strategy of "root camouflage" could explain the results we obtained with melon but not those obtained with flax. Indeed, Alabouvette et al. (2) reported the absence of any quantitative effect of melon roots on populations of Fusarium spp., whereas Lemanceau et al. (19) described a strong rhizosphere effect of flax on fluorescent pseudomonads. Other studies have reported variable degrees of genetic diversity among root-colonizing isolates of nonpathogenic F. oxysporum $(8,11,16)$. However, no clear conclusion concerning the influence of plant roots could be drawn from these studies, because root isolates were collected from different fields and were not directly compared to the corresponding soilborne populations.

Variable levels of genetic relatedness were found among IGS types resolved among soil and root isolates of $F$. oxysporum. IGS type 4 , which was highly represented among wheat isolates, showed a close relationship with IGS type 16 and, to a lesser extent, with 9 other IGS types. On the other hand, IGS type 11, which was frequent among tomato root isolates, was distantly related to all of the other IGS types. IGS types 4 and 11 were only distantly related to each other. It would be interesting to investigate whether the high level of divergence found between IGS type 11 and the other IGS types is related to other specific characteristics of these isolates.

In our study, the effect of two plant species on the soilborne populations of $F$. oxysporum was demonstrated clearly. Differences between populations were resolved on the basis of their IGS types. One might expect that these genotypic differences could be related to phenotypic differences. Studies on other microbial populations have reported a good correlation between genotypic and phenotypic characterization of subpopulations associated with plant roots (19,21). Lemanceau at al. (19) and Mavingui et al. (21) sug- 
gested a relationship between plant root selection of specific populations from soil and their ability to metabolize particular organic compounds. It would be interesting to characterize isolates of $F$. oxysporum for their ability to assimilate different substrates to generate hypotheses concerning the mechanisms of adaptation of F. oxysporum populations to tomato and wheat roots. Variations in phenotypes could be responsible for differences in the efficiency of root colonization and differences in antagonistic activity. This work is currently under investigation.

\section{ACKNOWLEDGMENTS}

This work was partly supported by the Conseil Régional de Bourgogne. We thank P. Lemanceau for critical evaluations and suggestions.

\section{LITERATURE CITED}

1. Alabouvette, C. 1990. Biological control of Fusarium wilt pathogens in suppressive soils. Pages 27-43 in: Biological Control of Soil-borne Plant Pathogens. D. Hornby, ed. CAB International, Wallingford, England.

2. Alabouvette, C., Couteaudier, Y., and Louvet, J. 1984. Recherche sur la résistance des sols aux maladies. IX. Dynamique des populations de $F u$ sarium spp. et de $F$. oxysporum f. sp. melonis dans un sol résistant et dans un sol sensible aux fusarioses vasculaires. Agronomie 4:729-733.

3. Alabouvette, C., Hoeper, H., Lemanceau, P., and Steinberg, C. 1996. Soil suppressiveness to diseases induced by soilborne plant pathogens. Pages 371-413 in: Soil Biochemistry. Vol. 9. G. Stotzky and J. M. Bollag, eds. Marcel Dekker, Inc., New York.

4. Alabouvette, C., Lemanceau, P., and Steinberg, C. 1993. Recent advances in biological control of Fusarium wilts. Pestic. Sci. 37:365-373.

5. Appel, D. J., and Gordon, T. R. 1994. Local and regional variation in populations of Fusarium oxysporum from agricultural field soils. Phytopathology 84:786-791.

6. Appel, D. J., and Gordon, T. R. 1996. Relationships among pathogenic and nonpathogenic isolates of Fusarium oxysporum based on the partial sequence of the intergenic spacer region of the ribosomal DNA. Mol. Plant-Microbe Interact. 9:125-138.

7. Burgess, L. W. 1981. General ecology of the Fusaria. Pages 225-235 in: Fusarium: Disease, Biology, and Taxonomy. P. E. Nelson, T. A. Toussoun, and R. J. Cook, eds. The Pennsylvania University Press, University Park.

8. Correll, J. C., Puhalla, J. E., and Schneider, R. W. 1986. Vegetative compatibility groups among nonpathogenic root-colonizing strains of Fusarium oxysporum. Can. J. Bot. 64:2358-2361.

9. Couteaudier, Y., and Alabouvette, C. 1990. Quantitative comparison of Fusarium oxysporum competitiveness in relation to carbon utilization. FEMS Microbiol. Ecol. 74:261-268.

10. Edel, V., Steinberg, C., Avelange, I., Laguerre, G., and Alabouvette, C. 1995. Comparison of three molecular methods for the characterization of Fusarium oxysporum strains. Phytopathology 85:579-585.

11. Elias, K. S., Schneider, R. W., and Lear, M. M. 1991. Analysis of vegetative compatibility groups in nonpathogenic populations of Fusarium oxyspor- um isolated from symptomless tomato roots. Can. J. Bot. 69:2089-2094.

12. Eparvier, A., and Alabouvette, C. 1994. Use of ELISA and GUS-transformed strains to study competition between pathogenic and nonpathogenic Fusarium oxysporum for root colonization. Biocontrol Sci. Technol. 4:35-47.

13. Gilbert, G. S., Handelsman, J., and Parke, J. L. 1994. Root camouflage and disease control. Phytopathology 84:222-225.

14. Gordon, T. R., and Okamoto, D. 1991. Vegetative compatibility groupings in a local population of Fusarium oxysporum. Can. J. Bot. 69:168-172.

15. Gordon, T. R., and Okamoto, D. 1992. Variation within and between populations of Fusarium oxysporum based on vegetative compatibility and mitochondrial DNA. Can. J. Bot. 70:1211-1217.

16. Katan, T., Berliner, R., and Katan, J. 1994. Vegetative compatibility in populations of Fusarium oxysporum from wild carnation. Mycol. Res. 98:1415-1418.

17. Komada, H. 1975. Development of a selective medium for quantitative isolation of Fusarium oxysporum from natural soil. Rev. Plant Prot. Res. 8:114-124.

18. Larkin, R. P., Hopkins, D. L., and Martin, F. N. 1996. Suppression of Fusarium wilt of watermelon by nonpathogenic Fusarium oxysporum and other microorganisms recovered from a disease-suppressive soil. Phytopathology 86:812-819.

19. Lemanceau, P., Corberand, T., Gardan, L., Latour, X., Laguerre, G., Boeufgras, J.-M., and Alabouvette, C. 1995. Effect of two plant species, flax (Linum usitatissimum L.) and tomato (Lycopersicon esculentum Mill.), on the diversity of soilborne populations of fluorescent pseudomonads. Appl. Environ. Microbiol. 61:1004-1012.

20. Lynch, J. M., and Whipps, J. M. 1990. Substrate flow in the rhizosphere. Plant Soil 129:1-10.

21. Mavingui, P., Laguerre, G., Berge, O., and Heulin, T. 1992. Genetic and phenotypic diversity of Bacillus polymyxa in soil and in the wheat rhizosphere. Appl. Environ. Microbiol. 58:1894-1903.

22. Miller, H. J., Henken, G., and Van Veen, J. A. 1989. Variation and composition of bacterial populations in the rhizospheres of maize, wheat, and grass cultivars. Can. J. Microbiol. 35:656-660.

23. Nelson, P. E., Toussoun, T. A., and Cook, R. J. 1981. Fusarium: Disease, Biology, and Taxonomy. The Pennsylvania State University Press, University Park.

24. Nelson, P. E., Toussoun, T. A., and Marasas, W. F. O. 1983. Fusarium Species: An Illustrated Manual for Identification. The Pennsylvania State University Press, University Park.

25. Paulitz, T. C., Park, C. S., and Baker, R. 1987. Biological control of Fusarium wilt of cucumber with nonpathogenic isolates of Fusarium oxysporum. Can. J. Microbiol. 33:349-353.

26. Postma, J., and Rattink, H. 1992. Biological control of Fusarium wilt of carnation with a nonpathogenic isolate of Fusarium oxysporum. Can. J. Bot. 70:1199-1205.

27. Rouxel, F., Alabouvette, C., and Louvet, J. 1979. Recherches sur la résistance des sols aux maladies. IV. Mise en évidence du rôle des Fusarium autochtones dans la résistance d'un sol à la fusariose vasculaire du melon. Ann. Phytopathol. 11:199-207.

28. Swofford, D. L. 1993. PAUP: Phylogenetic Analysis Using Parsimony. Version 3-1.1. Illinois Natural History Survey, Champaign. 